\title{
New UK council to curb psychiatry
}

A new UK-based organization aims to combat overdiagnosis and overtreatment in psychiatry. In an effort to bridge the gap between researchers, clinicians and the public, the Council for EvidenceBased Psychiatry (CEP) was launched by academic James Davies and media entrepreneur Luke Montagu at the UK House of Lords on Apr. 30.

"Much of the critical academic research into the adverse effects of psychiatric drugs and diagnoses are not reaching the public, nor is the public aware of which institutions can resolve these problems," stated Davies in an email interview. Davies and Montagu have backgrounds in medical anthropology, education and media.

"We will lobby for increased transparency and accountability with respect to the financial ties between industry and psychiatry, increase awareness regarding the rates of over prescription of anti-psychotic medications, and advocate for increased support from the British Medical Association, Royal Colleges, and Department of Health for people suffering from powerful withdrawal effects of both benzodiazepines and antidepressants," wrote Davies. CEP also plans to undertake research into underreported areas of psychiatric harms.

Although well-intentioned, CEP's manifesto is a tall order, particularly as the organization receives no public or private funding and has no permanent staff. It relies on volunteers to carry out activities.

Montagu and Davies believe that the success and growth of the council will hinge on their experience with media and keeping costs down.

"If more people knew about the problems associated with psychiatric practice and medications, this would put greater pressure on the institutional and individual leaders of the profession to institute reform," states Davies.

The council is backed by eminent psychiatrists and academics. Professor

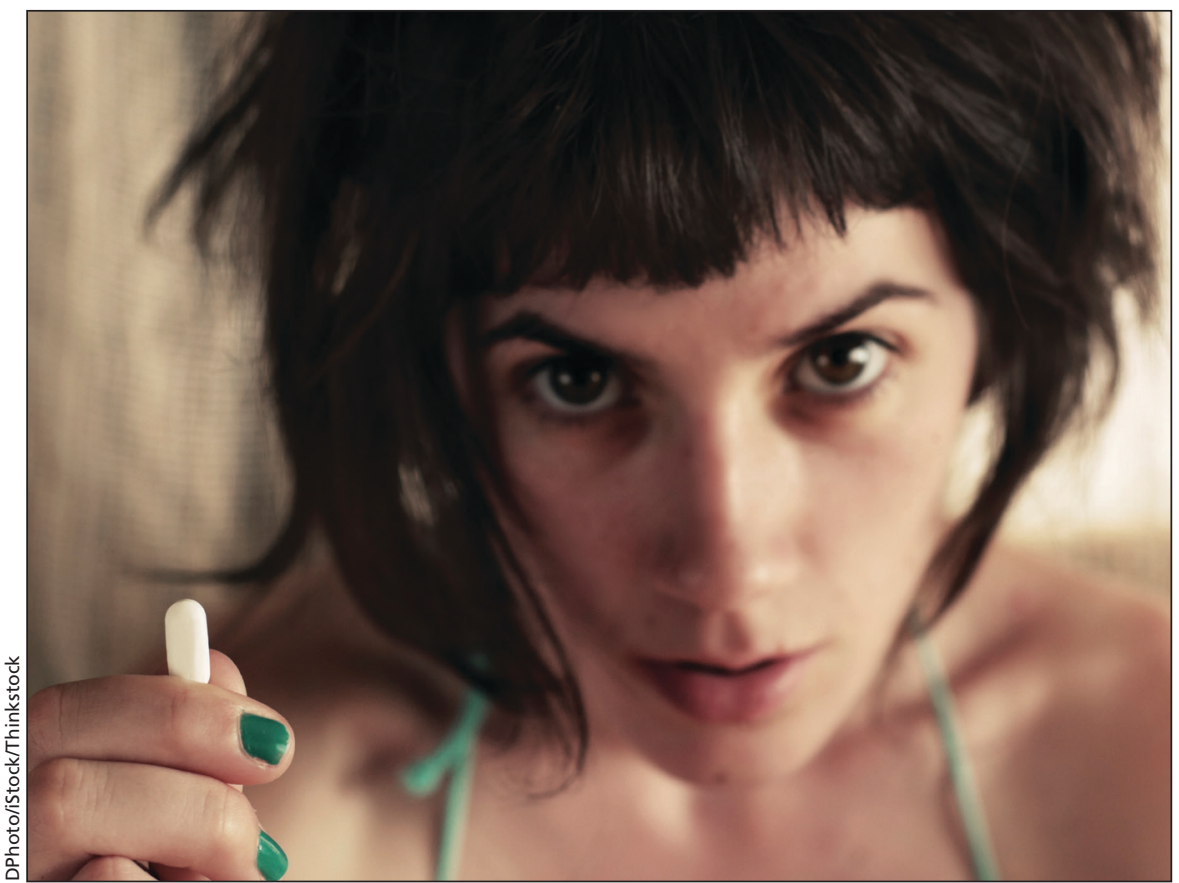

Not even 1 in 10 severely depressed patients benefits from antidepressants, says professor Peter Gøtzsche, a council supporter.

Peter Gøtzsche, cofounder of the Cochrane Collaboration and director of the Nordic Cochrane Centre, gave a keynote speech at its launch. "In psychiatry, clinicians are seduced by their clinical experience, which is incredibly misleading," said Gøtzsche.

"Not even 1 in 10 severely depressed patients benefit from antidepressants," Gøtzsche continued. "I've heard psychiatrists say that maybe antidepressants aren't that effective, but at least the patient benefits from the placebo effect. But the pill offered is not an inert substance and can be very harmful."

Worldwide, selective serotonin reuptake inhibitors (SSRIs) are often offered as first-line treatment for depression. Common side effects include sexual dysfunction and difficulty stopping treatment. One of the CEP's main goals is to publicize the harmful effects of psychiatric medication.

Speaking to CMAJ, Gøtzsche further commented, "Attention-deficit/ hyperactivity disorder (ADHD) is also overtreated." He mentioned an April
2012 CMAJ study where prescriptions for ADHD medications were higher $41 \%$ for boys and $77 \%$ for girls - if the child was born in December compared to January. "This is because those born in January have had 11 months more to develop their brains and social skills. A watch and wait approach to see if symptoms resolve spontaneously would be prudent in many cases."

In 2000, Gøtzsche published a landmark study in The Lancet concluding that screening for breast cancer with mammography is unjustified. Since then, he has spent his career informing the public of the harms of overdiagnosis in medicine and campaigning for increased clinical data transparency.

"In both mammography screening and psychiatric medicine, many people have ignored the serious harms, and flawed research has been the basis for authoritative guidelines. People are slowly waking up to these facts." Neil Chanchlani, MBChB, London, UK

CMAJ 2014. DOI:10.1503/cmaj.109-4814 